\title{
Pengaruh Livelihood Asset terhadap Livelihood Strategies Masyarakat Tepi Hutan di UB Forest Desa Tawangargo Kecamatan Karangploso Kabupaten Malang
}

\author{
The influence of Livelihood Asset against the Livelihood Strategies of the \\ community banks of forest in Tawangargo Village sub district Forest UB \\ Karangploso Malang
}

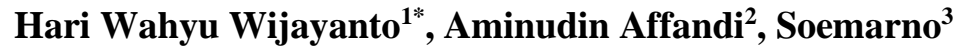 \\ ${ }^{1}$ Program Magister Pengelolaan Sumberdaya Lingkungan dan Pembangunan, PSUB \\ ${ }^{2}$ Jurusan Hama Penyakit Tanaman, Fakultas Pertanian, Universitas Brawijaya, Jalan Veteran 65145, \\ Malang, Indonesia \\ ${ }^{3}$ Jurusan Tanah, Fakultas Pertanian, Universitas Brawijaya, Jalan Veteran 65145, Malang, Indonesia
}

Received: 3 May 2019; Revised: 8 May 2019; Accepted: 9 May 2019

\begin{abstract}
ABSTRAK
Perubahan lingkungan hutan berdampak terhadap kondisi aset penghidupan maysarakat dan menyebabkan beragamnya strategi penghidupan masyarakat sekitar hutan. Penelitian ini bertujuan untuk menganalisis pengaruh aset penghidupan (livelihood asset) masyarakat sekitar hutan terhadap strategi penghidupan (livelihood straregy) yang mereka lakukan. Penelitian ini dilakukan di UB Forest Desa Tawangargo Kabupaten Malang. Responden penelitian ini adalah masyarakat sekitar UB forest dengan jumlah sampel sebanyak 105 responden. Metode yang digunakan adalah Structure Equation Modelling (SEM). Hasil penelitian menunjukkan bahwa aset memiliki positif terhadap strategi penghidupan. Sementara itu, demografi memiliki pengaruh negatif terhadap strategi penghidupan masyarakat sekitar hutan. Akan tetapi demografi akan memiliki pengaruh positif terhadap strategi penghidupan ketika masyarakat memiliki aset penghidupan. Hal ini menyiratkan bahwa perlu adanya peningkatan kepemilikan asset masyarakat tepi hutan untuk mempertahankan bahkan meningkatkan penghidupan mereka.
\end{abstract}

Kata kunci: aset penghidupan; strategi penghidupan; Structure Equation Modelling (SEM)

\section{ABSTRACT}

Forest environmental changes affect the condition of assets and caused various livelihood strategies of livelihood of communities around the forest. This research aims to analyze the effect of livelihood assets community forests against the strategy of livelihood that they do. This research was conducted in the village of Tawangargo forest in UB Malang. The respondents of the research is community around UB forest as much as 105 samples. The method used is the Structure Equation Modelling (SEM). The results showed that the assets have positive economic strategy. Meanwhile, the demographics of the potential negative effect against the local community livelihood strategies of forest. But demographics will have positive influence towards a strategy of livelihood when the society has assets of livelihood. This implies that the need for increased ownership of the assets of the edge of the forest community to maintain even the enhance their livelihood.

Keyword: livelihood asset; livelihood strategies; Structure Equation Modelling (SEM)

How to cite:

Wijayanto, H. W., Affandi, A., \& Soemarno. (2019). Pengaruh Livelihood Asset terhadap Livelihood Strategies Masyarakat Tepi Hutan di UB Forest Desa Tawangargo Kecamatan Karangploso Kabupaten Malang. HABITAT, 30(2), 54-61. https://doi.org/10.21776/ub.habitat.2019.030.2.7

\section{Pendahuluan}

Hutan merupakan salah satu ekosistem yang memeiliki fungsi penting bagi pembangunan

dan kehidupan manusia, baik fungsi ekologi sebagai tempat berlangsungnya siklus ekologis Available online at HABITAT website: http://www.habitat.ub.ac.id

ISSN: 0853-5167 (p); 2338-2007 (e) 
dari komponen air dan kehidupan flora dan fauna. Disamping itu juga memiliki fungsi sosial ekonomi bagi penduduk disekitarnya yang secara langsung berkaitan. Dalam beberapa tahun terakhir peran hutan dalam ekonomi pembangunan menjadi perhatian yang sangat penting (Hogarth et al., 2013). Beberapa studi telah membuktikan bahwa keberadaan hutan dalam suatu daerah memiliki hubungan positif terhadap kesejahteraan masyarakat disekitar (Sunderlin et al., 2008). Hal ini dikarenakan hutan merupakan sumberdaya alam yang dapat dimanfaatkan oleh masyarakat. Akan tetapi seiring perkembangan zaman kondisi hutan mengalami banyak perubahan. Salah satu penyebabnya adalah terjadinya perubahan iklim. Perubahan iklim mangakibatkan terjadinya perubahan kondisi fisik dan biologis lingkungan (Moore \& Allrad, 2008). Selain itu Ying et al., (2013) menjelaskan bahwa perubahan lingkungan dari tahun ke tahun berdampak terhadap ekosistem di daerah hutan. Sehingga secara tidak langsung perubahan kondisi lingkungan hutan akan berpengaruh terhadap penghidupan masyarakat, terutama di sekitar lingkungan tersebut.

Kondisi lingkungan memiliki peran penting terhadap penghidupan masyarakat. Menurut Bedjeck et al (2010) perubahan lingkungan sangat berpengaruh terhadap asset penghidupan masyarakat. Di sisi lain, asset penghidupan menentukan kemampuan masyarakat dalam melakukan strategi penghidupan untuk memenuhi kebutuhan mereka (Ellis, 2000). Ding et al (2018) membuktikan bahwa asset penghidupan memiliki pengaruh signifikan terhadap strategi penghidupan masyarakat Mongolia dalam. Sehingga dapat disimpulkan asset penghidupan yang dimiliki oleh masyarkat hutan berdampak terhadap strategi penghidupan mereka.

${ }^{*}$ Penulis Korespondensi.

E-mail: hariwahyu.wijayanto@gmail.com

Telp: 081333503079
Study tentang penghidupan masyarakat telah banyak dilakukan salah satunya Penelitian yang dilakukan oleh Rasmussen et al., (2017) menemukan bahwa hutan memiliki peran yang signifikan terhadap penghidupan masyarakat, karena hutan merupakan sumber mata pencaharian bagi masyarakat sekitar. Ali \& Rahut (2018) menemukan bahwa masyarakat sekitar hutan yang menerapkan kosep livelihood memiliki pendapatan dan kesejateraan yang lebih tinggi. Disamping itu, di Bangladesh kemampuan akses masyarakat terhadap strategi penghidupan sangat bergantung terhadap aset yang mereka miliki (Kibria et al., 2018). Dari beberapa penelitian yang telah ada, masih sedikit penelitian yang menggunakan alat analisis statistik untuk mengkaji penghidupan masyarakat sekitar hutan. Penelitian ini mencoba untuk menganalisis dampak asset penghidupan masyarakat hutan terhadap strategi penghidupan yang mereka lakukan.

\section{Metode Penelitian}

\subsection{Lokasi Penelitian}

Penentuan lokasi penelitian dilakukan secara purposive atau pemilihan lokasi yang dipilih secara khusus berdasarkan tujuan penelitian yaitu di Desa Tawangargo Kecamatan Karangploso Kabupaten Malang.

\subsection{Data Penelitian}

Data yang digunakan dalam penelitian ini yaitu data primer dan data sekunder. Data primer yang digunakan terdiri dari karakteristik, livelihood asset dan livelihood strategies sedangkan data sekunder yang digunakan yaitu keadaan umum lokasi penelitian. Teknik pengumpulan data yang digunakan dalam penelitian yaitu observasi, wawancara terstruktur, wawancara mendalam (indepth interview), dokumentasi dan kepustakaan.tabel 1 menyajikan statistik deskriptif data dalam penelitian ini.

Tabel 1. Statistik Deskriptif

\begin{tabular}{|c|c|c|c|}
\hline Variable & Definisi & Mean & Std. Dev. \\
\hline \multicolumn{4}{|c|}{ Demografi } \\
\hline Usia & Umur (Tahun) & 46.68 & 11.44 \\
\hline $\begin{array}{l}\text { Tanggungan } \\
\text { Keluarga }\end{array}$ & $\begin{array}{l}\text { Jumlah Anggota Rumah Tangga Yang Jadi Tanggungan } \\
\text { (Orang) }\end{array}$ & 2.83 & 1.02 \\
\hline Pendapatan & Total Pendapatan (Rupiah/bulan) & 11600000 & 7300000 \\
\hline Pendidikan & Tahun & 1.89 & 0.68 \\
\hline
\end{tabular}




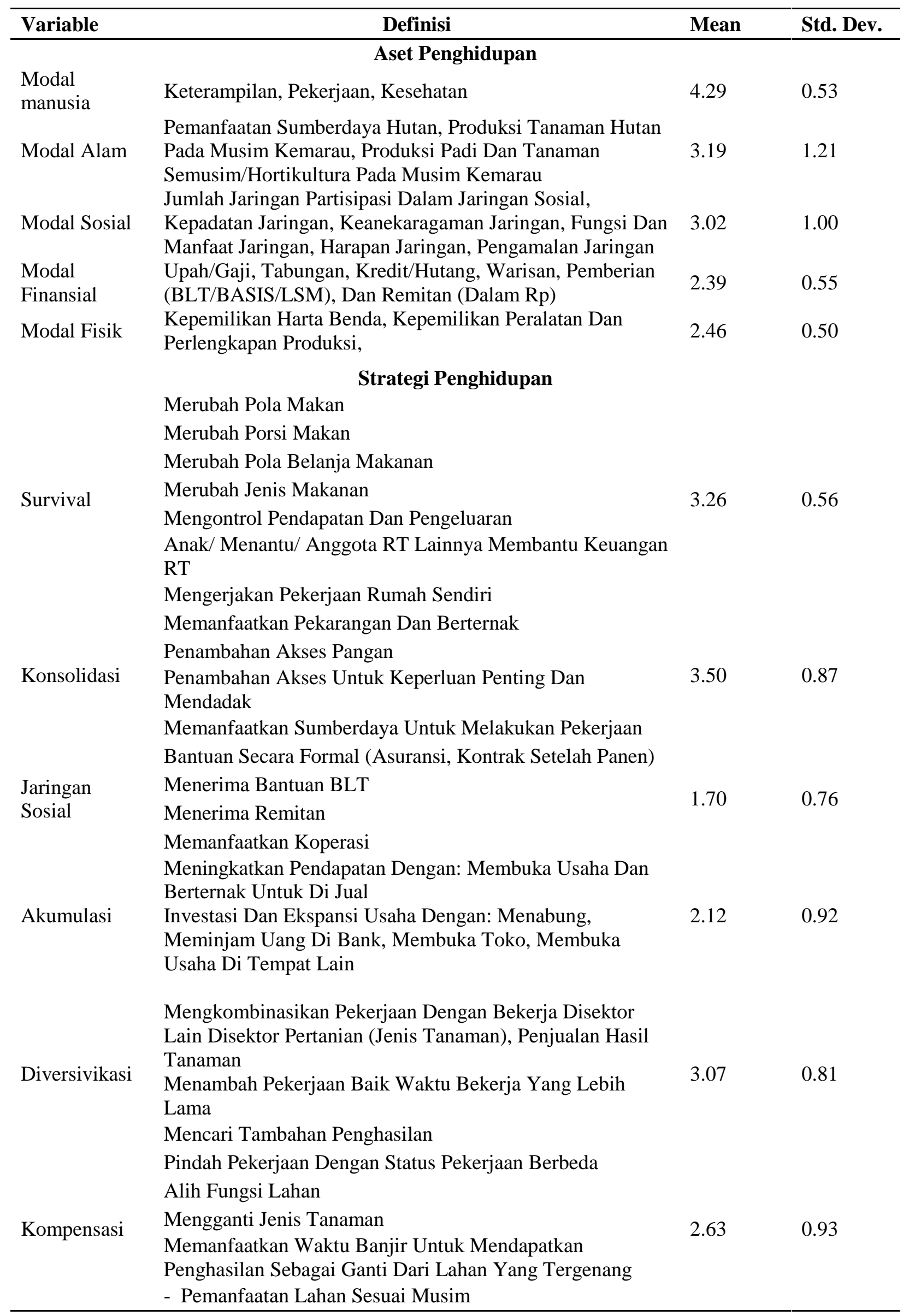




\subsection{Analisis Data}

\subsubsection{Uji Keabsahan Data}

Agar kuesioner dalam penelitian ini dapat diandalkan untuk melakukan pengumpulan data yang ada di lapangan, perlu dilakukan uji validitas dan uji reliabilitas. Menurut Livingston (2018), suatu alat ukur dikatakan valid apabila pertanyaan dalam kuisoner tersebut mampu mengungkapkan sesuatu yang akan diukur oleh kuesioner tersebut. Suatu alat ukur yang valid dapat menjalankan fungsinya sebagai alat ukur dengan tepat dan akurat sesuai dengan maksud dikenakannya tes tersebut. Fungsi dari uji reliabilitas adalah untuk mengetahui bahwa alat ukur tersebut reliabel atau handal apabila jawaban sampel terhadap pernyataan konsisten dari waktu ke waktu.

Berdasarkan uraian di atas, uji validitas dan reliabilitas sangat perlu untuk dilakukan agar instrumen penelitian ini dapat diandalkan. Apabila instrumen dalam suatu penelitian tidak dapat diandalkan, berarti data-data yang didapatkan tidak akan mampu menggambarkan kondisi yang ada di lapangan. Instrumen dalam penelitian ini dikatakan valid dan reliabel apabila nilai $r_{\text {hitung }}>$ rtabel.

\subsubsection{Structure Equation Modelling (SEM)}

Analisis data penelitian menggunakan pendekatan kuantitatif dan kualitatif. Analisis data secara kuantitatif menggunakan deskriptif statistik dan menggunakan Structure Equation Modelling - Partial Least Squares (SEM-PLS). SEM-PLS selain dapat digunakan sebagai konfirmasi teori juga dapat digunakan untuk merekomendasikan hubungan yang ada atau belum dan juga mengusulkan proposisi pengujian selanjutnya. SEM-PLS merupakan metode analisis yang power full yang tidak didasarkan banyak asumsi dan memungkinkan dilakukan analisis dari berbagai indikator variabel laten baik indikator bersifat refleksif dan formatif. SEM-PLS memberi kelonggaran kepada pengguna untuk menggunakan skala pengukuran selain interval seperti data nominal, ordinal dan data rasio dimana hal ini tidak diijinkan dalam SEM yang berbasis kovarian yang selama ini kita kenal (Monecke \& Leisch, 2012). Analisis kualitatif digunakan untuk menginterpretasikan secara mendalam terhadap angka persentase dalam bentuk deskriptif kualitatif yang diperkuat dari wawancara mendalam.

\section{Hasil dan Pembahasan}

\subsection{Uji Reliabilitas}

Untuk melakukan analisis reliabiliti, koefisien Cronbach's $\alpha$ diperlukan untuk mengukur masing-masing indikator dari variabel yang diamati. Hasil perhitungan nilai Cronbach's $\alpha$ dari masing-masing variabel lebih tinggi dari nilai $r$ tabel dengan signifikansi $5 \%$, yaitu sebesar 0,1614 . Hal ini berarti indikator pada masingmasing variabel adalah reliabel (Widiyanto, 2012).

\subsection{Uji Validitas}

Validitas adalah indeks yang menunjukkan sejauh mana suatu alat ukur betul-betul mengukur apa yang perlu diukur. Jika suatu instrumen pengukuran sudah valid (sah) berarti instrumen tersebut dapat mengukur benda dengan tepat sesuai dengan apa yang ingin diukur. Hasil uji validitas dapat dilihat pada Tabel 2 .

Tabel 2. Hasil Uji Validitas

\begin{tabular}{lll}
\hline Keterangan Nilai & Kesimpulan \\
\hline $\begin{array}{l}\text { Average path } \\
\text { coefficient (APC) }\end{array}$ & $\mathrm{P}<0,001$ & Valid \\
$\begin{array}{l}\text { Average R-Squared } \\
\text { (ARS) }\end{array}$ & $\mathrm{P}<0,001$ & Valid \\
$\begin{array}{l}\text { Average block VIF } \\
\text { (AVIF) }\end{array}$ & 1,063 & Valid \\
\hline
\end{tabular}

Berdasarkan tabel di atas, diketahui bahwa hasil output general result mempunyai kesesuaian validitas yang baik, dimana nilai $P$-value untuk Average PathCoefficient (APC) dan Average $R$ Squared (ARS) $<0.05$ begitu juga dengan nilai Average Variance Inflation Factor (AVIF) yang dihasilkan yaitu $1,063<5$, yang berarti bahwa tidak ada masalah multi kolonieritas antar variable eksogen, sehingga dapat dikatakan valid.

\subsection{Uji Goodness of Fit}

Pada bagian ini, disajikan informasi statistik dari uji Goodness of Fit dari output WarpPLS untuk membuktikan apakah model dalam penelitian ini sudah fit.Tabel 3 . menunjukkan hasil dari uji Goodness of Fit untuk keseluruhan model.

Berdasarkan hasil uji goodness of fit, terdapat delapan syarat yang goodfit, satu syarat yang fit, dan satu syarat dinyatakan marginal fit.Berdasarkan hasil tersebut, dapat dikatakan bahwa model yang dibentuk sudah fit atau baik. 
Tabel 3. Uji Goodness of Fit untuk Keseluruhan Model

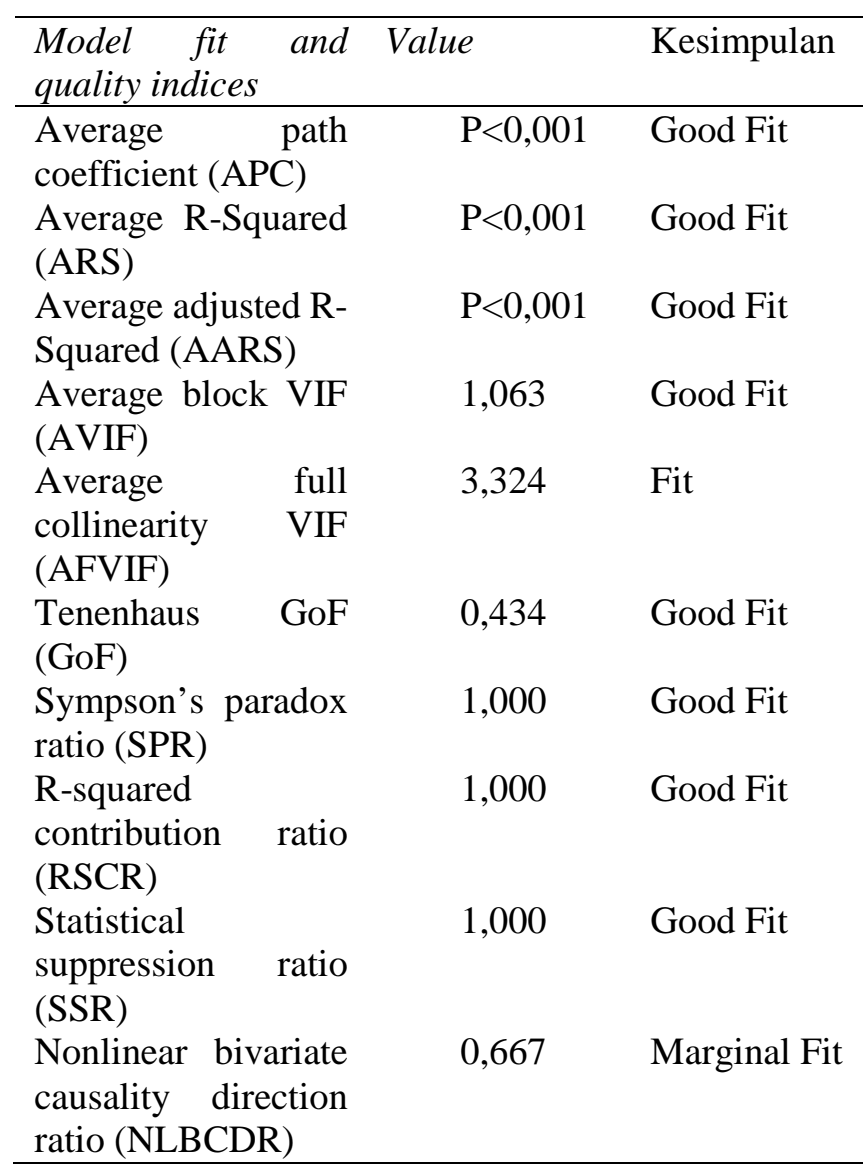

\subsection{Parameter Indikator}

Parameter model adalah unsur-unsur numerik yang merupakan acuan yang dapat menjelaskan batas-batas atau bagian-bagian tertentu dari suatu model. Terdapat tiga konsep variabel dalam penelitian ini, yaitu aset, demografi, dan strategi penghidupan. Berdasarkan Gambar 1 dapat diketahui bahwa modal manusia, alam, sosial, financial dan fisik memiliki pengaruh yang postif terhadap aset yang dimiliki. Modal fisik memiliki pengaruh yang paling besar terhadap kepemiliki aset. Modal fisik meliputi transportasi, bangunan, air bersih dan sanitasi, energy dan akses komunikasi. Hal tersebut sangat mendukung masyarakat dalam peningkatan ekonomi dan kesehatan. Sehingga modal fisik perlu menjadi perhatian masyarakat dan pihak terkait agar terjadi peningkatan dalam strategi penghidupan. Temuan ini sejalan dengan hasilhasil penelitian sebelumnya tentang hubungan antara berbagai bentuk kapital (modal) dengan aset penghidupan dan strategi penghidupan masyarakat (Ellis, 1998; Sunderlin et al., 2005; Naughton-Treves, Holland dan Brandon, 2005; Babulo et al., 2008; Kamanga, Vedeld dan
Sjaastad, 2009; Oyesola, 2010; Kareithi, 2010; Oyesola, 2010; Van-Dijk, 2011; Nawrotzki, Hunter dan Dickinson, 2012; Xu, 2012; Kibria, Jashimuddin and Makoto, 2014; Abdullah, et al., 2016; Kibria et al., 2018).

Strategi penghidupan mencerminkan strategi yang berpengaruh positif dalam penghidupan, yaitu strategi konsolidasi, memanfaatkan jaringan, akumulasi, diversifikasi dan kompensasi; sedangkan strategi survival berpengaruh negative (Mahdi, Shivakoti dan Schmidt-Vogt, 2009; Soltani dan Angelsen, 2012). Artinya bila penghidupan masyarakat lebih baik maka strategi survival tidak dipilih. Strategi survival dipilih bila pendapatan masyarakat rendah dan hanya cukup untuk memenuhi kebutuhan hidup sehari-hari. Sehingga pada saat masyarakat sudah memiliki pendapatan yang meningkat, mereka cenderung memilih strategi konsolidasi, memanfaatkan jaringan dan teknologi, akumulasi, diversifikasi atau kompensasi atau kombinasi dari beberapa strategi tersebut (Mohapatra dan Suar, 2008). Adapun strategi yang paling berpengaruh adalah strategi kompensasi dimana strategi tersebut merupakan strategi masyarakat yang sudah mulai fokus pada pekerjaan tertentu dan menghasilkan untuk jangka panjang.Koefisien Variabel Laten

Tabel 4 menunjukkan analisis koefisien variabel laten pada penelitian ini. Nilai p-value skewness dan kurtois kurang dari 0,001, sedangkan nilai dari kurtois sendiri kurang dari 25. Hal tersebut menunjukkan bahwa metode estimasi maximum likelihood masih valid (Retnoningsih, 2014).

\subsection{Koefesien Variabel Laten}

Tabel 4 menunjukkan analisis koefisien variabel laten pada penelitian ini. Nilai $p$-value skewness dan kurtois kurang dari 0,001, sedangkan nilai dari kurtois sendiri kurang dari 25. Hal tersebut menunjukkan bahwa metode estimasi maximum likelihood masih valid (Kim, 2015; Retnoningsih, 2014).

\subsection{Indirect Effect dan Total Effect}

Berdasarkan tabel 5 dan table 6, diketahui total effect dari aset ke strategi penghidupan sebesar 0,922. Hal tersebut berarti bahwa variabel aset berpengaruh positif terhadap strategi penghidupan sebesar $92,2 \%$. Sementara itu, total effect dari demografi ke strategi penghidupan sebesar -0,074. Hal tersebut berarti bahwa variabel demografi berpengaruh negatif terhadap strategi penghidupan sebesar 7,4\%. Hal ini menunjukkan 
bahwa kepemilikan aset mempengaruhi responden dalam mennetukan strategi penghidupan yang dipilih. Demografi baru memiliki pengaruh yang positif bila memiliki aset, hal tersebut dapat dilihat dari indirect effect dari aset terhadap strategi penghidupan hal ini sejalan dengan temuan Ding et al (2018), dimana livelihood asset memiliki pengaruh signifikan terhadap strategi penghidupan yang dilakukan oleh masyarakat.

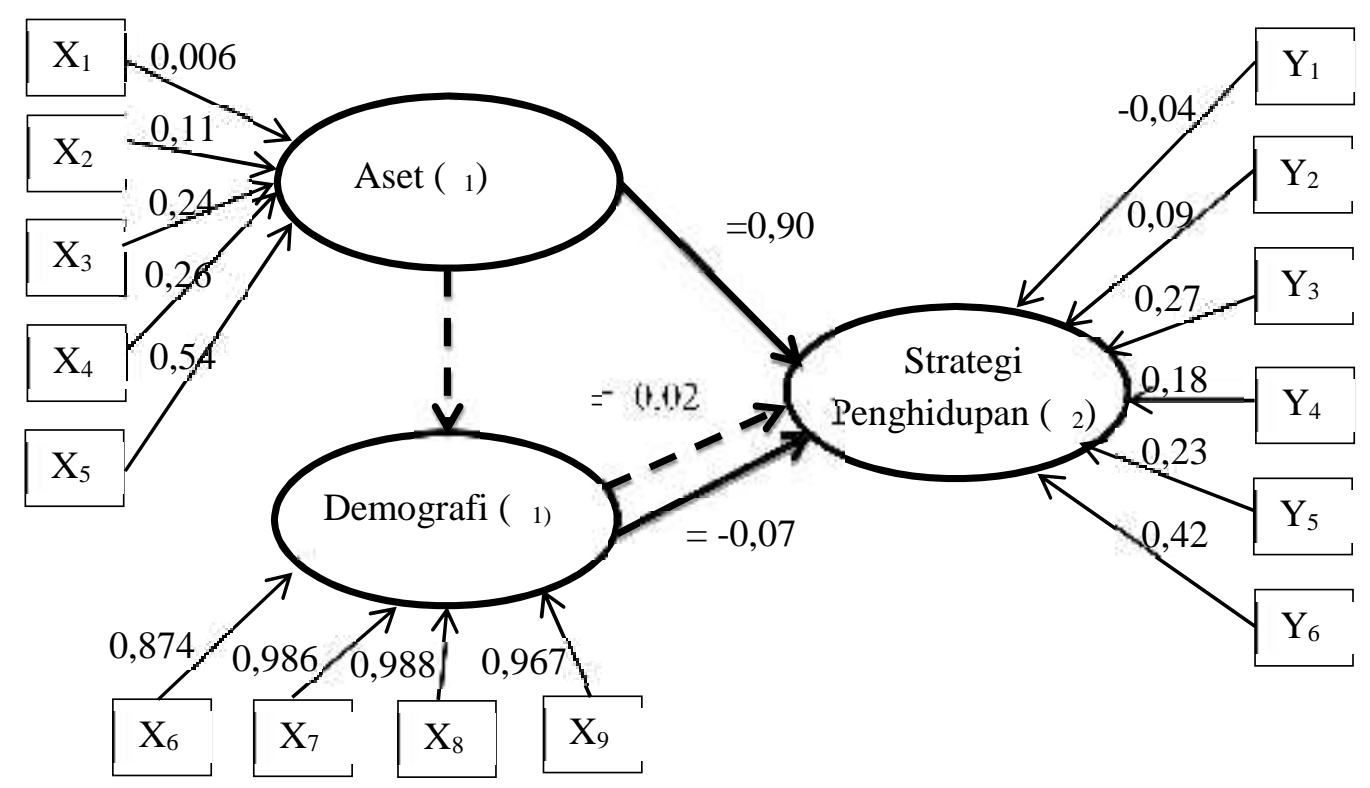

Gambar 1. Path Diagram Akhir dari Keseluruhan Model

Tabel 4. Koefisien Variabel Laten

\begin{tabular}{llll}
\hline Keterangan & Aset & Demografi & Strategi Penghidupan \\
\hline R-squared coefficients & a & 0,092 & 0,848 \\
Adjusted R-squared coefficients & a & 0,083 & 0,845 \\
Composite reliability coefficient & 0,929 & 0,828 & 0,863 \\
Cronbach's alpha coefficient & 0,919 & 0,715 & 0,840 \\
Average variance extracted & 0,331 & 0,572 & 0,298 \\
Full collinearity VIFs & 4,388 & 1,072 & 5,412 \\
Q-squared coefficient & a & 0,089 & 0,833 \\
Minimum values & $-1,544$ & $-2,160$ & $-2,048$ \\
Maximum values & 1,749 & 1,441 & 1,558 \\
Medians & $-0,274$ & 0,257 & $-0,007$ \\
Modes & 0,989 & 0,365 & 0,793 \\
Skewness coefficient & $0,169$ (p-value $<0,001)$ & $-0,657$ & $-0,446$ \\
& & $(p-v a l u e ~<0,001)$ & \\
Exc. Kurtois coefficient & $-1,381$ & $-0,649$ & $-0,739$ \\
Rohatgi-Szekely & No & Yes & Yes \\
Klaassen-Mokveld-van Es & Yes & Yes & Yes \\
Jarque-Bera & No & No & Yes \\
Robust Jarque-Bera & No & No & Yes \\
\hline
\end{tabular}


Tabel 5. Indirect Effect

\begin{tabular}{lllll}
\hline & Aset & Demografi & SP & Keterangan \\
\hline \multirow{4}{*}{ Strategi Penghidupan } & 0,372 & - & - & $P$-value \\
& 0,069 & - & - & Standard errors \\
& 0,021 & & & Effect sizes \\
& 0,022 & - & - & Indirect effects for paths \\
\hline
\end{tabular}

Tabel 6. Direct Effect

\begin{tabular}{lllllllll}
\hline & \multicolumn{2}{l}{ Direct Effect } & \multicolumn{2}{l}{ Indirect Effect } & \multicolumn{2}{l}{ Total Effect } & \multirow{2}{*}{ Ket } \\
\cline { 2 - 7 } Aset & Demografi & Aset & Demografi & Aset & Demografi & \\
\hline \multirow{4}{*}{ Demografi } & $<0,001$ & - & - & - & $<0,001$ & - & 1 \\
& 0,090 & - & - & - & 0,090 & - & 2 \\
& 0,092 & - & - & - & 0,092 & - & 3 \\
SP & $-0,303$ & - & - & - & $-0,303$ & - & 4 \\
& $<0,001$ & 0,220 & 0,372 & - & $<0,001$ & 0,220 & 1 \\
& 0,007 & 0,096 & 0,069 & - & 0,076 & 0,096 & 2 \\
& 0,826 & 0,022 & 0,021 & - & 0,847 & 0,022 & 3 \\
& 0,90 & $-0,074$ & 0,022 & - & 0,922 & $-0,074$ & 4 \\
\hline
\end{tabular}

Keterangan: (1) P-value, (2) Standard errors, (3) Effect sizes, (4) Effects for paths

\section{Kesimpulan}

Dari hasil penelitian dapat disimpulkan bahwa asset penghidupan masyarakat tepi hutan di UB Forest Desa Tawangargo Kecamatan Karangploso Kabupaten Malang memiliki pengaruh positif terhadap strategi penghidupan yang mereka lakukan. Disamping itu sosiodemografi masyarakat memiliki pengaruh negative terhadap strategi penghidupan. Yang artinya ketika nilai variabel demografi semakin tinggi maka strategi penghidupan yang mereka lakukan akan semakin rendah. Akan tetapi demografi akan memiliki pengaruh positif terhadap strategi penghidupan ketika masyarakat tepi hutan memiliki asset penghidupan. Sehingga untuk mempertahankan bahkan meningkatkan penghidupan masyarakat tepi hutan perlu meningkatkan asset yang mereka miliki.

\section{Daftar Pustaka}

Abdullah, M., N.Abu, N.Stacey, S.T.Garnett and B.Myers. 2016. Economic dependence on mangrove forest resources for livelihoods in the Sundarbans, Bangladesh. Forest Policy Econ., 64: 15-24.

Babulo,B., Muys, B., Nega, F., Tollens, E., Nyssen, J., Deckers, J., Mathijs, E., 2008. Household livelihood strategies and forest dependence in the highlands of Tigray, Northern Ethiopia. Agric. Syst., 98: 147155.
Ellis, F. 2000. Rural livelihoods and diversity in Developing Countries. Oxford: Oxford University Press.

Ellis,F. 1998. Household strategies and rural livelihood diversification. Journal of Development Studies, 35(1):1-38.

Hogarth, N. J., Belcher, B., Campbell, B. and Stacey, N. 2013. The Role of ForestRelated Income in Household Economies and Rural Livelihoods in the BorderRegion of Southern China. World Development, 43, 111-123.

Kamanga,P., P.Vedeld and E.Sjaastad. 2009. Forest incomes and rural livelihoods in Chiradzulu District, Malawi. Ecol. Econ., 68: 613-624.

Kareithi, J.N. 2010. Declining social capital and vulnerability to livelihood risks in Turkana district. Kenya, 11: 33-46.

Kibria, A. S. M. G., Costanza, R., Groves, C., \& Behie, A. M. (2018). The interactions between livelihood capitals and access of local communities to the forest provisioning services of the Sundarbans Mangrove Forest, Bangladesh. Ecosystem Services, $32, \quad 41-49$. doi:10.1016/j.ecoser.2018.05.003

Kibria, A.G., M.Jashimuddin and I.Makoto. 2014. Effects of participatory forest management on livelihood capitals of the community in 
Cox's Bazar, Bangladesh. J. Forest Res., 19: 42-51.

Kibria,A.S.M.G., R.Costanza, C.Groves and A.M. Behie. 2018. The interactions between livelihood capitals and access of local communities to the forest provisioning services of the Sundarbans Mangrove Forest, Bangladesh. Ecosystem Services, 32: 41-49.

Kim, N. (2015). Tests Based on Skewness and Kurtosis for Multivariate Normality. Communications for Statistical Applications and Methods, 22(4), 361-375. doi:10.5351/csam.2015.22.4.361

Livingston S., A. (2018). Test Reliability-Basic Concepts Educational Testing Service, Princeton, New Jersey

Mahdi, G.Shivakoti and D.Schmidt-Vogt. 2009. Livelihood change and livelihood sustainability in the uplands of Lembang subwatershed, West Sumatra, Indonesia, in a changing natural resource management context. Environmental Management, 43(1):84-99.

Mohapatra,B. and D.Suar. 2008. Technological Capital and Sustainable Livelihood-Does Technological Capital of Watershed Influence Sustainable Livelihood? Int. J. Rural Manag., 4: 213-236.

Monecke, A., \& Leisch, F. (2012). semPLS: Structural Equation Modeling Using Partial Least Squares. Journal of Statistical Software, 48(3). doi:10.18637/jss.v048.i03

Moore,B. and G.Allard. 2008. Climate Change Impact on forest Health, Forestry Department Food and Agriculture Organization of the United Nations. Rome, Italy

Naughton-Treves,L., M.B.Holland and K.Brandon. 2005. The role of protected areas in conserving biodiversity and sustaining local livelihoods. Annual Review of Environment and Resources, 30:219-252.

Nawrotzki,R.J., L.M.Hunter and T.W.Dickinson. 2012. Rural livelihoods and access to natural capital: Differences between migrants and non-migrants in Madagascar. Demographic research, 26, 10.4054
Oyesola,O.B. 2010. Effects of capital assets on livelihood diversification of rural households in Oyo State Nigeria. Journal of Agriculture, Forestry and the Social Sciences, 8(1):xx.

Rasmussen, L. V., Watkins, C., \& Agrawal, A. (2017). Forest contributions to livelihoods in changing agriculture-forest landscapes. Forest Policy and Economics, 84, 1-8. doi:10.1016/j.forpol.2017.04.010

Retnoningsih, D. 2014. Hubungan Rantai Pasok (Supply Chain Relationship) Dan Daya Saing Usaha Kecil Menengah (UKM) Sari Apel di Kota Batu. Agrise. Volume XIV No.1 BulanJanuari 2014.

Soltani,A. and A.Angelsen. 2012. Poverty, sustainability, and household livelihood strategies in Zagros, Iran. Ecol. Econ., 79: 60-70.

Sunderlin, W. D., Angelsen, A., Belcher, B., Burgers, P., Nasi, R., Santoso, L. and Wunder. 2005. Livelihoods, forests, and conservation in developing countries: An Overview. World Development, 33(9): 1383-1402. doi:10.1016/j.worlddev.2004.10.004

Sunderlin,W.D., A.Angelsen, B.Belcher, P.Burgers, R.Nasi, L.Santoso, and S.Wunder. 2005. Livelihoods, Forests, and Conservation in Developing Countries: An Overview. World Development, 33 (9): 1383-1402.

Van-Dijk,T. 2011. Livelihoods, capitals and livelihood trajectories: A more sociological conceptualization. Prog. Dev. Stud., 11: 101-117.

Widiyanto, J. 2012. SPSS for Windows. Badan Penerbit FKIP UMS. Surakarta.

Xu,H.S. 2012. Livelihood capital, livelihood risk and livelihood strategies for farmers. Issues Agric. Econ., 10: 100-106.

Ying,X.W., Z.Chun-Yu and J.Qing-Yu. 2013. Impacts of Climate Change on Forest Ecosystems in Northeast China. Advances in Climate Change Research, 4(4): 230 241. doi: 10.3724/sp.j.1248.2013.230 